\title{
INFLUENCE OF DIFFERENT ASSEMBLIES ON PRE- HEATING THE HSLA SAR 80T STEEL ON COATED ELECTRODE WELDING
}

\author{
J. S. Bastos ${ }^{\text {a }}$ \\ C. A. M. Ferreira ${ }^{a}$ \\ M. C. L. Souza ${ }^{a}$, \\ J. S. Dias ${ }^{b}$, \\ and N. C. O. Tapanes \\ ${ }^{a}$ Centro Universitário Estadual da Zona Oeste \\ Engineering School \\ Av. Manuel Caldeira de Alvarenga, 1203, Rio \\ de Janeiro - RJ, 23070-200, Brasil \\ mauroclsouza@hotmail.com \\ ${ }^{\mathrm{b}} \mathrm{CEFET} / \mathrm{RJ}$ \\ UNED Itaguai \\ Rod. Gov. Mário Covas, s/n - Santana, Itaguaí \\ - RJ. 23812-101 Brasil. \\ Received: Aug 18, 2020 \\ Revised: Oct 25, 2020 \\ Accepted: Dec 14, 2020

\section{NOMENCLATURE} \\ HSLA High Strength Low Alloy \\ AWS American Welding Society \\ SAR High Resistence Weldables \\ LE Elasticity Limit \\ LR Resistance Limit \\ AL Stretching \\ Ch V Charpy V-notch impact test
}

\section{ABSTRACT}

The present work evaluated the influence of assemblies other than preheating in the welding process obtained by coated electrode, using high strength and low alloy steel SAR 80T as the base metal and the AWS E7018 electrode as the addition metal. In order to prevent cracks, preheating and interpassing for low alloy steel was performed. Depending on the way the preheating equipment is installed, it may take more or less time to reach the preheat temperature. Different assembly arrangements for top joints were evaluated, aiming at cost reduction, in addition to evaluations of the mechanical properties of the joint. Visual testing, ultrasound, micrography, macrography and cross-sectional traction were performed. The results obtained were considered acceptable and showed that there was an influence on time, cost of preheating and resistance to impact.

Keywords: ARBL steels; addition electrode; preheating; crack; cost

\section{INTRODUCTION}

Low alloy steel is commonly used in special components that require high strength. The proper use of these steels inevitably depends on their weldability, which must meet mechanical and chemical requirements, but without ever forgetting the other major problems of the welded joint, that is, deformation and defects (Bezerra, 2005).

Some steels, low alloy, contain low carbon content (around $0.1 \%$ ), therefore susceptible to the formation of martensitic structures when subjected to heating and rapid cooling, as is characteristic of the welding operation (Lancaster, 1992). Studies have been carried out to obtain crystalline structures composed of Bainite and Martensite Biphasic that would have a good combination between hardness and impact resistance (Jiang et al., 2002 and Linnert, 2014).

To avoid cracks caused by shrinkage of the weld and by hydrogen content after the welding operation, manufacturers recommend preheating (Usiminas, 2014).

The present study aims to evaluate the influence of the assembly of the preheat layout in the welding process by electrode coated on SAR 80T steel. Because it is a very significant factor in the welding process of high-strength steels, the preheating assembly was chosen as the object of the study (Modenesi et al, 1985). The choice of SAR 80T steel is due to its importance in the construction of offshore equipment such as equipment called bellmouths, essential for oil extraction in floating platform systems. It is expected to find differences in the crystalline structure of the welded joint and work execution times.

\section{MATERIAL AND METHODS}

\section{Material}

Three samples were used as base material to perform the SAR $80 \mathrm{~T}$ welding in the following dimensions: 2 (two) samples with $25 \mathrm{~mm}$ x $400 \mathrm{~mm}$ x 
$600 \mathrm{~mm}$ and 1 (one) sample with $25 \mathrm{~mm}$ x $600 \mathrm{~mm} \mathrm{x}$ $600 \mathrm{~mm}$.

The samples were dimensioned in order to assemble the preheating system in three different Layouts, according to figures 1,2 and 3 presented later. The base material has the following chemical composition, as shown in Table 1.

Table 1. Chemical composition of the base metal (\%)

\begin{tabular}{|c|c|c|c|c|c|c|}
\hline Al & B & C & $\mathrm{Cr}$ & $\mathrm{Cu}$ & Mn & Mo \\
\hline$\leq 20$ & $\leq 0,005$ & $\begin{array}{c}0,06 \mathrm{a} \\
0,28 \\
\end{array}$ & $\leq 5,25$ & $\leq 1,8$ & $\begin{array}{c}0,35 a \\
1,6 \\
\end{array}$ & $\begin{array}{c}\leq \\
0,65\end{array}$ \\
\hline $\mathrm{Nb}$ & $\mathbf{P}$ & s & Si & $\mathrm{Ti}$ & $\mathrm{Zr}$ & \\
\hline$\leq 0,1$ & $\begin{array}{c}0,01 \mathrm{a} \\
0,12\end{array}$ & $\begin{array}{c}0,01 \mathrm{a} \\
0,12\end{array}$ & $\begin{array}{c}0,01 \mathrm{a} \\
0,9\end{array}$ & $\leq 0,05$ & $\leq 0,12$ & \\
\hline
\end{tabular}

\section{Addition metal}

With the AWS A 5.5 standard (AWS A 5.5, 2014) as a guideline, the AWS E7018 electrode was determined as the welding consumable for the samples in this study. This electrode is indicated for low alloy steel structures, with $740 \mathrm{MPa}$ of tensile strength or more and thickness above $1 / 2$ ". Tables 2,3 and 4 show the chemical compositions and mechanical functions, chemical properties and mechanical properties of the consumable deposited as welded, according to data provided by the manufacturer.

The addition material, as established by the AWS A5.5 2014 and ESAB 2005, has the following chemical composition (Table 2 ).

Table 2. Chemical composition of the wire (core)

\begin{tabular}{|c|c|c|c|c|c|c|}
\hline CLASS & $\mathrm{Mn}$ & $\mathrm{Si}$ & $\mathrm{Ni}$ & $\mathrm{Cr}$ & $\mathrm{Mo}$ & $\mathrm{V}$ \\
\hline E7018 & $\leq 1,60$ & $\leq 1,60$ & $\leq 0,30$ & $\leq 0,20$ & $\leq 0,30$ & $\leq 0,008$ \\
\hline \multicolumn{7}{|c}{$\mathrm{Mn}+\mathrm{Ni}+\mathrm{Cr}+\mathrm{Mo}+\mathrm{V} \leq 1,75$}
\end{tabular}

The addition material, as established by the AWS A5.5 2014 and ESAB 2005 (ESAB, 2005), has the following composition (Table 3 ).

Table 3. Composition of the coating (Class E7018)

\begin{tabular}{|c|c|}
\hline \multicolumn{2}{|c|}{ COMPOSITION } \\
\hline Calcium carbonate & $30 \%$ \\
\hline fluorite $\left(\mathrm{CaF}_{2}\right)$ & $20 \%$ \\
\hline Iron-manganese & $5 \%$ \\
\hline potassium silicate & $15 \%$ \\
\hline iron powder & $30 \%$ \\
\hline moisture & $0,10 \%$ \\
\hline FUNCTION & PROTECTION \\
\hline gas former - fluxing agent & \multirow{5}{*}{$\begin{array}{l}80 \% \mathrm{CO} \\
20 \% \mathrm{CO}_{2}\end{array}$} \\
\hline slag former - fluxing agent & \\
\hline deoxidizing - iron - alloy & \\
\hline binder - arc stabilizer & \\
\hline deposition agent & \\
\hline
\end{tabular}

The addition material, as established by the AWS A5.5 2014 and ESAB 2005, has the following mechanical properties (Table 4).
Table 4. Mechanical properties of filler metal. (Class E7018)

\begin{tabular}{|c|c|c|c|c|c|}
\hline $\begin{array}{c}\text { LE } \\
(\mathrm{MPa})\end{array}$ & $\begin{array}{c}\mathrm{LR} \\
(\mathrm{MPa})\end{array}$ & $\begin{array}{c}\text { AL } \\
(\%)\end{array}$ & $\begin{array}{c}\text { Ch V } \\
\text { average } \\
(\mathrm{J})\end{array}$ & $\begin{array}{c}\text { Ch V } \\
\text { indiv. }(\mathrm{J})\end{array}$ & $\begin{array}{c}\text { Temperature } \\
\left({ }^{\circ} \mathrm{C}\right)\end{array}$ \\
\hline$\geq 399$ & $\geq 482$ & $\geq 22$ & $\geq 27$ & $\geq 20$ & -29 \\
\hline
\end{tabular}

\section{Assembling the sample preheating system}

The AM1 sample has the dimensions of $25 \mathrm{~mm}$ x $400 \mathrm{~mm}$ x $600 \mathrm{~mm}$, including weld inlets and outlets, this preheating layout followed a pattern predefined by the author, noting that the joint distance to the resistance was $60 \mathrm{~mm}$, shoulder that this distance is the object of this study and will vary in samples AM2 and AM3, as shown in Figure 1.

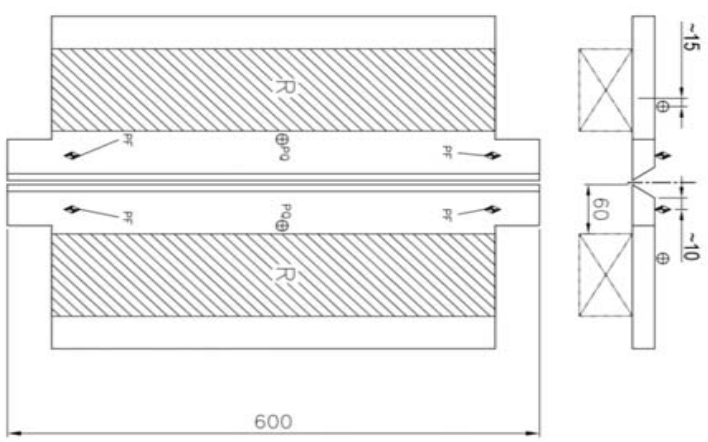

Figure 1. Sample preheating layout AM1.

The sample AM2 has the dimensions of $25 \mathrm{~mm}$ x $400 \mathrm{~mm}$ x $600 \mathrm{~mm}$, including the weld inlets and outlets, this preheating layout followed a pattern predefined by the author, noting that the distance from the joint to the resistance was $100 \mathrm{~mm}$, which differentiates between samples AM1 and AM3, as shown in Figure 2.

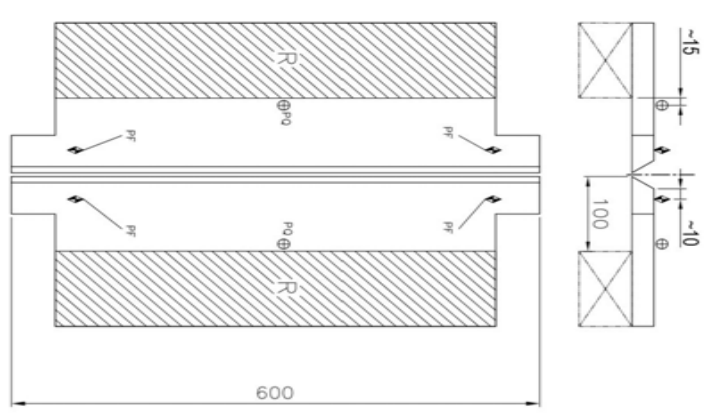

Figure 2. Sample preheating layout AM2.

The AM1 sample has the dimensions of $25 \mathrm{~mm}$ x $600 \mathrm{~mm}$ x $600 \mathrm{~mm}$, including weld inlets and outlets, this preheating layout followed a pattern predefined by the author, noting that the distance from the joint to the resistance was $200 \mathrm{~mm}$, which 
differentiates between samples AM1 and AM2, as shown in Figure 3.
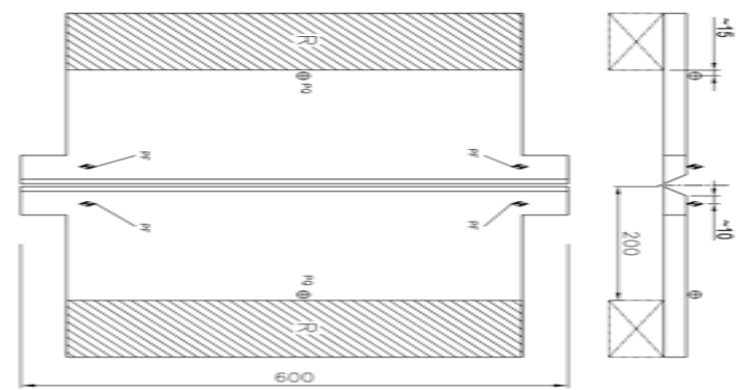

Figure 3. Sample preheating layout AM3

\section{Welding}

The assembly of the joint was carried out following the guidelines of the AWS 5.5 2014 standard, regarding the chamfer opening, angle and use of weld backing.

Figure 4 shows the dimensions and geometry configuration of the joint used together with the backing. The chamfer configuration complies with the AWS 5.5 2014 standard, which refers to welding by coated electrode.

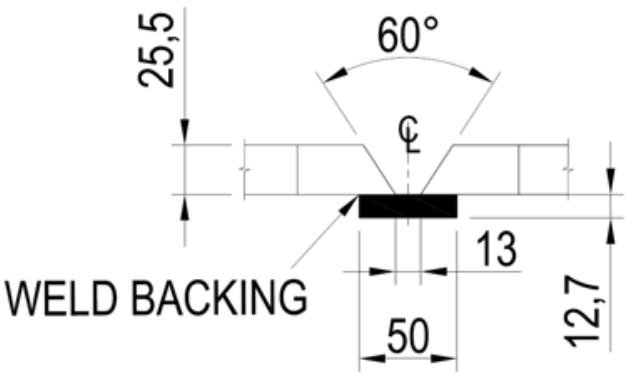

Figure 4 - Configuration of welded joint geometry

The joint was heated up to the preheating temperature according to the AWS 5.5 2014 standard, which recommends for welding obtained by the coated electrode E7018, have the preheating parameters with temperatures of $95^{\circ} \mathrm{C}-110^{\circ} \mathrm{C}$ to start welding and $200^{\circ} \mathrm{C}-225^{\circ} \mathrm{C}$ for interpass strands.

The sequence of deposition of coated electrode weld beads in the samples is shown in Figure 5.

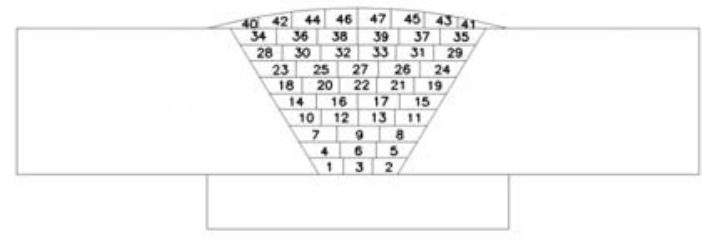

Figure 5 - Welding sequence with coated electrode
The string deposition sequence was defined with a view to taking advantage of the string temperature deposited in a superimposed form immediately on the previous string, applying tempering to the addition material in order to correct the toughness and excessive hardness, achieving an increase in toughness.

\section{Tests}

The specimens were removed from samples AM1, AM2, and AM3, according to the cutting plan shown in Figure 6 and manufactured according to the AWS 5.52014 standard.

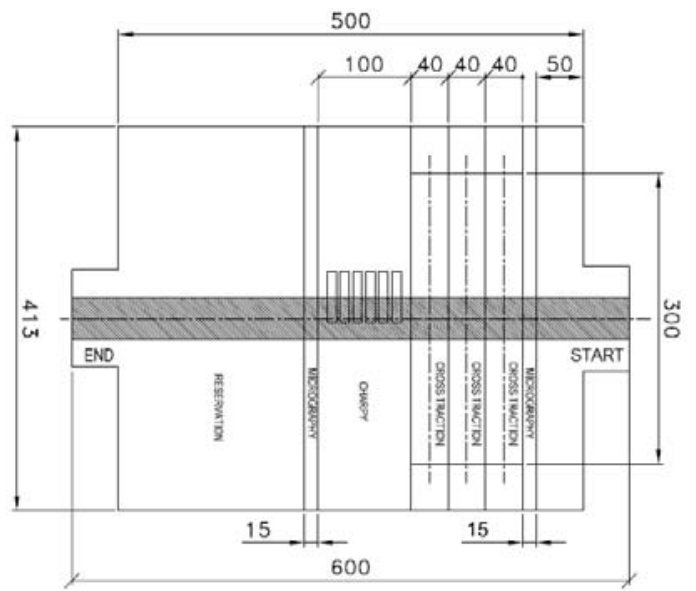

Figure 6 - Removal of specimens (units in $\mathrm{mm}$ )

The weld joint was prepared in the base material, using SAR 80T steel sheets by grinding and a penetrating liquid test was carried out on the chamfer faces.

A non-destructive visual inspection test was performed, as required in the AWS D1.1 standard, to determine the acceptance of the sample joints.

The non-destructive ultrasound test was performed, meeting the criteria of the AWS D1.1 standard, with the aid of the Olympus Epoch 600 ultrasound device, to assess possible defects and discontinuities in the sample joints. METYL CELULOSE was used as a coupling medium between the transducer (head) and the sample.

For conducting the Charpy impact tests at temperatures of $-10^{\circ} \mathrm{C}$ and $-18^{\circ} \mathrm{C}$, samples of $10 \mathrm{~mm}$ x $10 \mathrm{~mm}$ x $55 \mathrm{~mm}$ dimensions with "V" notch were extracted from the samples as established in the AWS 5.52014 standard.

The transverse tensile tests were carried out according to acceptance criteria specified by the type of material and the criteria of the AWS 5.5 2014 standard, are used to determine the limit of tensile strength of welds and chamfered joints.

In order to carry out a transversal traction test, 3 (three) specimens were removed from each sample, according to the AWS 5.52014 standard, in order to assist in the study of the resistance of the material 
used in the experiment, providing data that allowed a better analysis of the studied material.

Metallographic micrography and macrography tests were performed, the tests were performed with the aid of the LEICA DMi8 microscope. Surface preparation by sanding with granulometry of 600 , diamond paste for polishing, and chemical reagent Nital 7\%.

\section{RESULTS AND DISCUSSION}

All samples had the results within the acceptance criteria in the visual, ultrasound, transversal traction, macrography and micrography tests.

The non-destructive visual inspection test was applied to assess the acceptability of the weld, taking into account the criteria established by the AWS D1.1 2010 standard.

The AM1 sample showed insufficient deposition, with regard to weld reinforcement, but it did not preclude the manufacture of the specimens.

The three welded joints of the samples showed excellent quality, after performing the nondestructive ultrasound test with the aid of the Olympus Epoch 600 ultrasound device.

Table 5 - Results of the Charpy-V impact test

\begin{tabular}{|c|c|c|c|c|c|c|}
\hline & \multicolumn{3}{|c|}{ Base Metal $\left(-10^{\circ} \mathrm{C}\right)$} & \multicolumn{3}{c|}{ Addition Metal $\left(-18^{\circ} \mathrm{C}\right)$} \\
\hline SEQUENCE & AM1 & AM2 & AM3 & AM1 & AM2 & AM3 \\
\hline 1st TEST & 69,3 & 52,8 & 33,7 & 58,1 & 31,5 & 30,2 \\
\hline 2st TEST & 40,9 & 49,3 & 41 & 42,3 & 41,1 & 38,7 \\
\hline 3rd TEST & 63,6 & 57,2 & 36,8 & 67,4 & 43,6 & 34,6 \\
\hline MEDIUM & 57,9 & 53,1 & 37,2 & 55,9 & 38,7 & 34,5 \\
\hline
\end{tabular}

In the impact test, there was a variation between the results obtained in the specimens of the samples, where the toughness of the specimens of the AM1 sample showed a result superior to those presented by the specimens of the AM2 sample, this same result can be observed among the specimens of sample AM2 compared to specimens of sample AM3, that is, the further away the heating resistance, the more fragile the result, but all results above the reference value for the materials, results shown in Table 5 and in Figures 7 and 8.

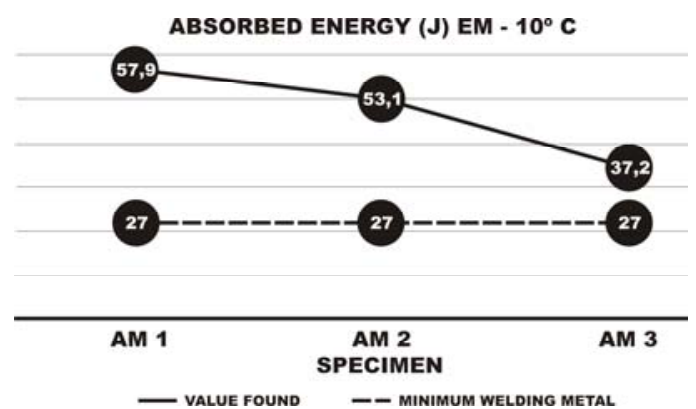

Figure 1 - Results of impact tests on the base metal

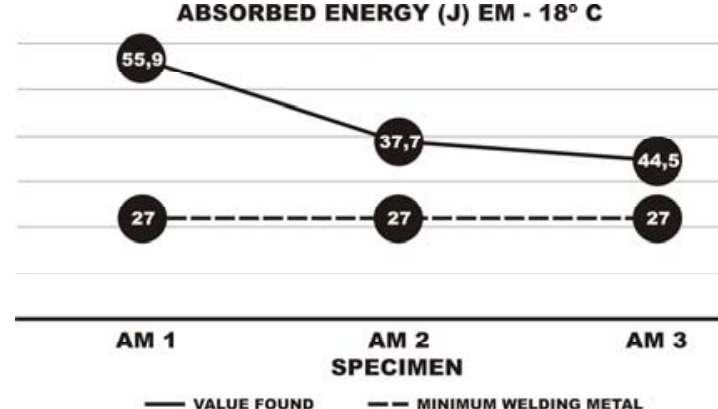

Figure 8 - Results of the impact tests on the filler metal

The transversal traction tests obtained little variation between the samples in relation to the resistance limit, according to Table 6 .

Table 6 - Values obtained in the testing of specimen samples

\begin{tabular}{|c|c|c|c|c|c|}
\hline & & & & \multicolumn{2}{|c|}{ Resistance } \\
\hline $\begin{array}{c}\text { Proof } \\
\text { bodies }\end{array}$ & $\begin{array}{c}\text { Thickness } \\
\mathrm{mm}\end{array}$ & $\begin{array}{c}\text { Width } \\
\mathrm{mm}\end{array}$ & $\begin{array}{c}\text { Section } \\
\mathrm{mm}^{2}\end{array}$ & $\begin{array}{c}\text { Maximum } \\
\text { load kgf }\end{array}$ & $\begin{array}{c}\text { Limit } \\
\text { Mpa }\end{array}$ \\
\hline AM1a & 11,99 & 18,98 & 227,57 & $19.339,99$ & 834 \\
\hline AM1b & 11,96 & 18,99 & 227,12 & $19.641,75$ & 848 \\
\hline AM1c & 11,98 & 18,97 & 227,26 & $19.867,65$ & 858 \\
\hline AM2a & 11,97 & 18,96 & 226,95 & $19.121,31$ & 827 \\
\hline AM2b & 11,95 & 18,93 & 226,21 & $19.954,34$ & 865 \\
\hline AM2c & 11,99 & 18,97 & 227,45 & $19.329,99$ & 833 \\
\hline AM3a & 11,93 & 18,95 & 226,07 & $19.853,29$ & 862 \\
\hline AM3b & 11,97 & 18,93 & 226,59 & $19.276,37$ & 835 \\
\hline AM3c & 11,96 & 18,99 & 227,12 & $19.392,84$ & 838 \\
\hline
\end{tabular}

* Specified threshold $760 \sim 960 \mathrm{MPa}$ and Break Location Out of weld

In the transverse tensile test, all specimens were approved, since the limit of rupture occurred within the range of values between $760 \mathrm{MPa}$ to $960 \mathrm{MPa}$, a criterion for this material and outside the welded joint.

The macrographic aspect of the welded joints, increased by $10 \mathrm{x}$, where a multipass welding process is observed, there were no surface discontinuities, showed that there was adequate penetration, having cast the V chamfer base, as shown in Figure 9. 


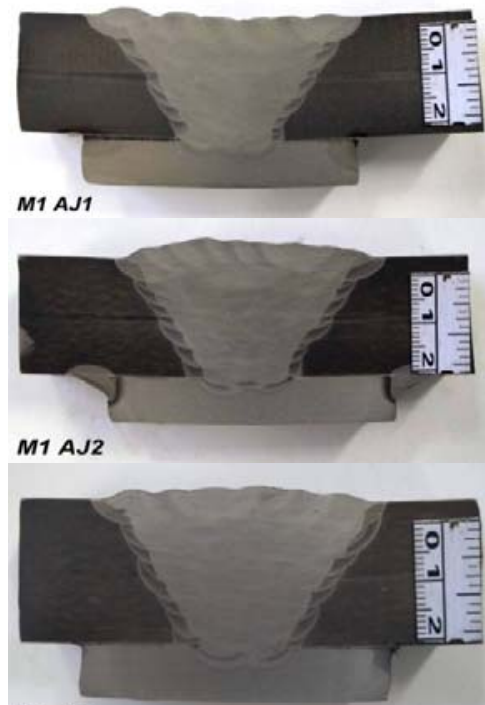

Figure 9 - Macrography of samples AM1, AM2 and AM3 respectively

In the result of the optical microscopy, it is concluded that in the three welding samples they presented the expected microstructure. In the region of the weld metal, it has a microstructure consisting of an acicular ferrite matrix (AF), polygonal ferrite (PF), and second phase ferrite (FSP) and the base metal has tempered martensite, according to the micrographs in Figure 10.

\section{AM1}

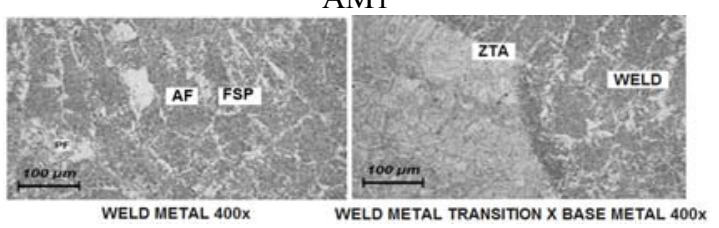
AM2

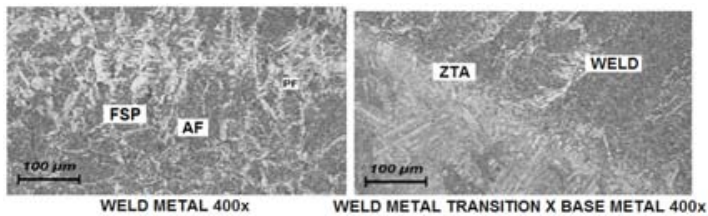
AM3

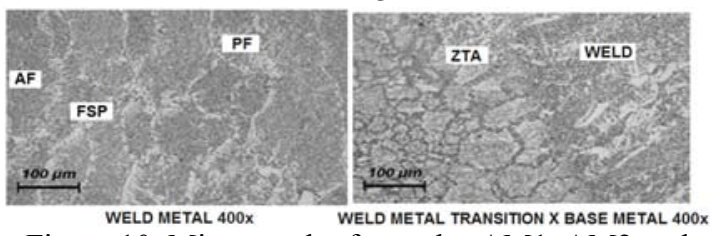

Figure 10. Micrograph of samples AM1, AM2 and

AM3 respectively

The cost of preheating the samples, counted until the joint reaches the start welding temperature, had a gradual variation directly linked to the distance between the heating resistance and the joint to be welded.

Considering the labor, equipment and infrastructure costs involved in the welding process, the cost was presented as follows, as shown in Table7.

Table 7 - Cost of preheating the joint

\begin{tabular}{|c|c|c|c|}
\hline ITEMS & \multicolumn{3}{|c|}{ COST } \\
\hline $\begin{array}{c}\text { Samples / } \\
\text { Joint } \\
\text { distance }\end{array}$ & AM1 / 60 mm & AM2 / 100 mm & $\mathrm{AM} / 200 \mathrm{~mm}$ \\
\hline Time & $9 \mathrm{~min}$. & $15 \mathrm{~min}$. & $35 \mathrm{~min}$. \\
\hline Labor & $\mathrm{R} \$ 5,02$ & $\mathrm{R} \$ 8,37$ & $\mathrm{R} \$ 19,52$ \\
\hline $\begin{array}{c}\text { Equipment / } \\
\text { Infrastructure }\end{array}$ & $\mathrm{R} \$ 0,07$ & $\mathrm{R} \$ 0,12$ & $\mathrm{R} \$ 0,28$ \\
\hline Total & $\mathrm{R} \$ 5,09$ & $\mathrm{R} \$ 8,49$ & $\mathrm{R} \$ 19,80$ \\
\hline
\end{tabular}

The AM1 sample, where the heating resistance was mounted $60 \mathrm{~mm}$ away from the welded joint, had a cost of $R \$ 5.09$ (five reais and nine cents), the AM2 sample where this distance was $100 \mathrm{~mm}$ the cost was R \$ 8.49 (eight reais and forty-nine cents) and finally the AM3 sample that had its resistance mounted at $200 \mathrm{~mm}$ the cost was R \$ 19.52 (nineteen reais and eighty cents), this variation in costs taking into account the time that each sample took to reach the welding start temperature.

\section{CONCLUSIONS}

We can observe that the different assemblies of the preheating system did not interfere in the quality of the welded joint, as for the results obtained in the visual, ultrasound, micrograph, macrography and transversal traction, however we can observe the direct interference in the time and cost of the preheating, where the samples that had the resistances assembled closer to the joint reached the start welding temperature in a shorter time than the others, in addition, there was a gradual variation in the impact resistance.

Finally, it is proposed to conduct a new research using a material that needs post-heating, to check also under these conditions.

\section{ACKNOWLEDGEMENTS}

The authors would like to thank Nuclebrás Equipamentos Pesados - Nuclep and Research Support Foundation of the State of Rio de Janeiro (FAPERJ) by support given to the study.

\section{REFERENCES}

AWS 5.5, 2014, Specification for Alloy Steel Electrodes for Shielded Metal Arc Welding.

Bezerra, A. A., 2005, Cold Welding, Sinergia, São Paulo, vol. 6, No.1, pp.71-76.

ESAB, 200, MIG / MAG Welding Handout.

Jiang, Y., Zhou, R., 2005, Microstructures and properties of bainite and martensite dual-phase cast steel fabricated by combination of alloying and 
controlled cooling heat treatment. Material Science Forum, vol. 475-479, pp. 93-96.

Lancaster, J. F., 1992, Handbook of Structural Welding, McGraw Hill Inc., New York, 436 pp., 1992.

Linnert, G. E., Welding Metallurgy; Fundamentals, 4th Ed., AWS, Miami, 950 pp., 1994.

Modenesi, P. J., Marques, P. V., Santos, D. B., 1985, Welding Metallurgy Course. Christiano Ottoni Foundation, UFMG School of Engineering, Belo Horizonte, Apostila 388 p.

Usiminas, 2014, Usiminas Catalog of Heavy Plates. 